
and Sally Burgess (Eds.), Publishing Research in English as an Additional Language: Practices, Pathways and Potentials. Adelaide: The University of Adelaide Press, 2017; 260 pp., ISBN 9781925261523 (hbk). Journal of Language and Education, 6(2), 190-192. https://doi.org/10.17323/jle.2020.10686

\title{
Margaret Cargill and Sally Burgess (Eds.), Publishing Research in English as an Additional Language: Practices, Pathways and Potentials. Adelaide: The University of Adelaide Press, 2017; 260 pp., ISBN 9781925261523 (hbk).
}

\author{
Hamed Barjesteh ${ }^{1}$, Elham Movafagh Ardestani ${ }^{1}$, Ahmad Modaberi ${ }^{2}$ \\ ${ }^{1}$ Islamic Azad University \\ ${ }^{2}$ Payame Noor University
}

Correspondence concerning this article should be addressed to Elham Movafagh Ardestani, Department of English Language and Literature, Ayatollah Amoli Branch, Islamic Azad University, Amol-Babol old Road, Amol, post box:678, Iran.E-mail:elham.movafagh55@gmail.com

Cargill and Burgess (2017) in their e-book entitled Publishing Research in English as an Additional Language: Practices, Pathways and Potentials aimed to add to students' and researchers' knowledge about academic writing for publication. This book consists of 12 chapters and was published by University of Adelaide Press. The first chapter of the book is about the life-history study of humanities scholars' responses to research evaluation policies in Spain. The second chapter is on research hardship in the social sciences. The third chapter is about academic advising, authors' editing, and translation in a graduate degree program. The fourth chapter covers different approaches to editing and their implications for the author-editor relationship. The fifth chapter is about the effectiveness of the CCC model in enabling and assessing change in text editing knowledge and skills in a blended-learning postgraduate course. In Chapter 6 , the book focuses on the factors needed for the selection of appropriate journals by researchers. In Chapter 7, journal conventions and practices are the focus, and information on medical research is also provided. Mentor training and development is a key focus of Chapter 8. In Chapter 9, interactions between a research supervisor and a group of master's and $\mathrm{PhD}$ students in a Chinese hospital was explained in the context of advising them on their research papers for publication. Chapter 10 is on plagiarism. Chapter 11 focuses on proper answers to externally imposed pressure. Finally, in Chapter 12, several unconventional aspects of academic writing were reported.

Chapter 1 is an attempt to focus on ways in which scholars respond to the changes in national and institutional policies that occur as a result of the

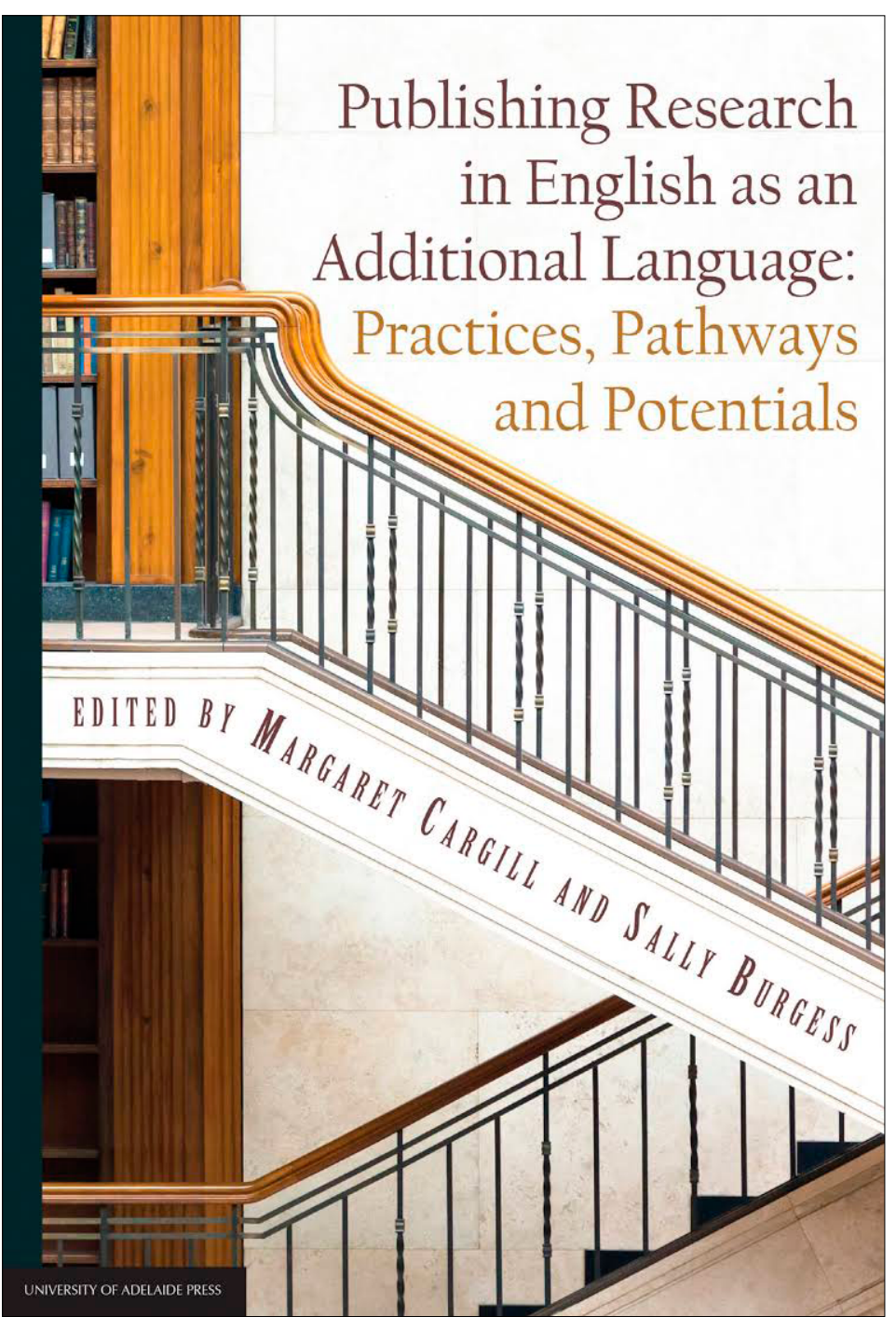


increasing pressure to publish in English. In this chapter, Burgess investigates changes in publication practices in Spain and the implications of these changes in the context of research assessment. The chapter focuses on the effect of these policies on Spanish scholars and can be compared with the experiences of scholars in many other contexts. To write this chapter, the life-history approach adopted by Connell and Wood (2002) was utilized. This approach was investigated by Connell (2006) in a series of case studies of Spanish humanities scholars.

Chapter 2 presents some research challenges in the social sciences. This chapter first argues that in the social sciences it is both relevant and important for the field of English for Research Publication Purposes (ERPP) and ERPP teachers to engage in methodology brokering the language development of learners while considering the global epistemological expectations of hardship in social research. In the next step, the chapter presents a description of the research writing matrix, in which language issues are addressed through the dialogic development of epistemologically credible research questions and an increased understanding of the underlying logic of the structure of research genres in the social sciences. Finally, the chapter shows how in a transcultural, critical-pragmatic pedagogy, inexperienced research writers can demonstrate their understanding of research rigour for their own communities, including data collection, analysis, and expected language structures.

In Chapter 3, DiGiacomo addresses the issue of intervention by examining the degree and nature of such interventions in a text produced by a novice author, in this case a doctoral candidate in the field of cultural anthropology preparing a thesis to be submitted in English in the context of the European Doctorate program. In this chapter, Cadman observes tensions in her role as an ERPP teacher, DiGiacomo sees challenges in the multiple roles she performs as co-supervisor of students' theses, copy editor, post-translation editor, and translator.

In Chapter 4, the authors carried out a comparative intervention study to probe their respective approaches to revising non-native English speakers' texts. The comparison of interactions between in-house and freelance editors with texts and with their author-clients is shown by the researcher. The researcher emphasizes using margin comments as key data points to help the authors when they are hoping to publish in international journals. In fact, the use of different approaches where the authors face problems publishing their research is mentioned.

In Chapter 5, Linnegar addresses how the CCC Model is effective in enabling and assessing change in text-editing knowledge and skills in a blended-learning postgraduate course with respect to the approach in which text editing quality is evaluated based on the five key levels of intervention: content, text type, structure, presentation, and wording. Linnegar in this chapter also describes a training program employing a blended-learning methodology in which a model termed the CCC model is used. The advantage of this model is the criteria used for the assessment of quality in text editing across the five levels of intervention with regard to the dimensions of consistency, correspondence, and correctness.

Chapter 6 provides information about the credibility of open access emerging journals. In this chapter, BocanegraValle first explores open access journals in the humanities, an area of research publication practice. Next, she notes that open access publication was once seen as partly dubious compared to privatized academic publishing, where the managers acquire large profits through subscription fees and, more recently, payments for individual downloads.

Chapter 7 mostly explores the degree of variability in the rhetorical structure of research papers published in different high-impact English language journals within a single sub-discipline of medicine: immunology and allergies. The results report that in the particular sub-discipline under study, two groups of journals that differ at both the macro-structural and micro-structural levels show a more or less promotional rhetorical style. It also mentions that the type of rhetorical variation identified in this study can mainly be explained in terms of three factors: readership expertise, journal scope, and the prevalent rhetorical practices in long-established versus emergent journals and their target audiences.

Chapter 8 is an attempt to lay the groundwork for discussions among scientists publishing research in English from Indonesia. In fact, this chapter focuses on mentor training and development. It also mentions that the pressure to publish papers in international journals can be for the sake of increasing PhD students who must publish their research findings based on their universities' requirements for PhD graduation. Added to the abovementioned information, the chapter reports outcomes recorded immediately post-intervention and findings from an interview study conducted after the participants had spent 12 months to learning how to publish research findings. 
Chapter 9 focuses on research supervision towards publication in a Chinese hospital. The study was part of a larger project that author conducted in the Orthopedics Department of a major Chinese hospital to investigate how research takes place in the department. The chapter, in the first step, provides a brief overview of the benefits of medical students' engagement in research and the challenges for Chinese hospitals in terms of their supervision. Next, it outlines the theoretical background of the study, as it was based on some tenets drawn from cultural-historical activity theory. Finally, the authors explored a supervisor's verbal communication while conducting research supervision at a Chinese hospital.

Chapter 10 addresses the geopolitics of academic plagiarism. First, it discusses how serious an offence academic plagiarism is. In fact, it mentions that, in different countries, plagiarism, like other forms of academic corruption, is not viewed with quite the same degree of criticism. Next, the author mentions some definitions of plagiarism. For example, modern dictionaries define academic plagiarism as the appropriation of the writings or ideas of another or as literary theft. Finally, the chapter deals with the usefulness and limitations of Gemeinschaft/ Gesellschaft model.

In Chapter 11, the authors mention the government policy reforms in many Asian countries to advance their own country's capacity to access and contribute to international knowledge repertoires. In this study the research context is Vietnam, and the pressure is for English language teachers to become researchers and conduct and publish research in ways accepted by Western academics. The research also aims to perceive how Freire's (1970) distinction between transformative and transmissive pedagogies is used in three classrooms through the interaction between recently encouraged innovative practices and conventional practices in which instructors control students' learning.

Finally, Chapter 12 deals with several unconventional aspects of academic writing, which include double-edged acknowledgments, a dangerous ESP textbook, an imaginary author, a public confession of pique, unusual imperatives, a highly critical review, narratives in the form of allegories or alternative histories, an egregious contract offer, and an attempt to modify biodata conventions. The chapter shows that authors can sometimes be ingenious or playful in their writing. For example, in their acknowledgments and footnotes, they detail how divergences from journal conventions are made not just by senior academic scholars but also those beginning their careers.

All in all, the challenges faced by scholars who need to publish in English as an additional language are covered in this book. The planning of writing, choosing a suitable target journal, using various methods employed by instructors and professional editors to help scholars plan their work, the CCC model, the guiding comments of supervisors, and the inline and margin comments of editors are some way to overcome the challenges academic writers face.

It is also clear that support offered to scholars as they aim for publication needs to be tailored to the particular culture, context and language experience and how to understand and deal with academic plagiarism.

\section{Conflict of interest}

The authors declare that they have no conflict of interest.

\section{References}

Cargill, M., \& Burgess, S. (Eds.). (2017). Publishing research in English as an additional language: practices, pathways and potentials. University of Adelaide Press.

Connell, R.W. (2006). Core activity: Reflexive intellectual workers and cultural crisis. Journal of Sociology, 42(1), 5-23. https://doi.org/10.1177/1440783306061350

Connell, R.W., \& Wood, J. (2002). Globalization and scientific labour: Patterns in a life history study of intellectual workers in the periphery. Journal of Sociology, 38(2), 167-190. https://doi.org/10.1177/144078302128756561

Freire, P. (1970). Pedagogy of the oppressed. Herder and Herder. 